\title{
Effects of load-induced micro-cracks on chloride penetration resistance in different types of concrete
}

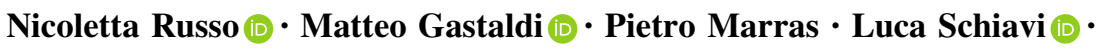 \\ Alberto Strini (iD) Federica Lollini $(\mathbb{B})$
}

Received: 29 May 2020/Accepted: 5 November 2020/Published online: 24 November 2020

(C) The Author(s) 2020

\begin{abstract}
Chloride penetration resistance of concrete is one of the key parameters for the durability design of reinforced concrete structures located in chloride-bearing environments. In all the current available durability models, service life is evaluated considering concrete in uncracked conditions, which is rarely found in practice. This work investigates chloride penetration resistance of concrete in uncracked and micro-cracked configurations, evaluated in terms of chloride migration coefficient through non-steady state migration test (Rapid Chloride Migration test). Prismatic specimens were manufactured considering six different concrete types and two different times of curing. In micro-cracked configuration, cracks were obtained with a specifically developed loading procedure. Micro-cracks were characterized at the end of the exposure test, in terms of crack width at the exposed surface and crack depth. Results showed that cracks were 5-70 $\mu \mathrm{m}$ wide and up to $40 \mathrm{~mm}$ deep, always causing an increase in chloride penetration, that should be evaluated considering both
\end{abstract}

N. Russo $(\bowtie) \cdot$ M. Gastaldi · F. Lollini

Department of Chemistry, Materials and Chemical Engineering "'Giulio Natta", Politecnico di Milano, Piazza Leonardo da Vinci 32, 20133 Milan, Italy e-mail: nicoletta.russo@polimi.it

P. Marras · L. Schiavi - A. Strini Istituto per le Tecnologie della Costruzione, Consiglio Nazionale delle Ricerche (ITC-CNR), Viale Lombardia 49, 20098 San Giuliano Milanese, Italy crack width and crack depth, with respect to sound conditions. The effects on the chloride penetration seemed to be more pronounced on the more impervious concretes.

Keywords Reinforced concrete durability - Cracked concrete $\cdot$ Load-induced micro-cracks $\cdot$ Chloride migration coefficient $\cdot$ Blended cements $\cdot$ Rapid Chloride Migration

\section{Introduction}

Chloride-induced corrosion of steel rebar is one of the main detrimental processes affecting the durability of reinforced concrete (RC) structures located in chloride-bearing environments [1]. In recent decades, significant efforts have been dedicated to deepen the knowledge of corrosion processes affecting steel reinforcement, and, as a result, to the development of numerous models for the durability design with regard to corrosion prevention. These models, however, present some critical issues, in particular they do not consider the effects of cracks in concrete [2]. In practice it is very common to find cracks in the concrete cover, and literature agrees that this may shorten the initial phase of service life, i.e. corrosion initiation of steel reinforcement [3]. The kinetic of the process is indeed regulated by the chloride penetration 
front, and in the case a crack is present in the concrete cover, a local increment of the chloride penetration front may occur, more or less pronounced according to the geometrical characteristics of the crack, shortening the initiation time.

Several studies have been carried out in recent years concerning the effects of cracks on chloride penetration and mass transport in concrete and mortars [4-24]. The studies in literature are characterized by several different cracking procedures, different methods to characterize crack geometrical parameters and different testing procedures. Cracks have been either simulated with artificial notches [4-7] or induced with mechanical loading procedures [8-22]. Artificial notches are controlled (known width and depth) and repeatable, anyway the smooth and parallel crack walls are far from reality. On the other hand, loadinduced cracks obtained with Brazilian splitting test [8-13] or expansive core method [14] generate tensile cracks in unreinforced concrete specimens of limited dimensions, but crack depth is not easily controllable and in most cases the crack crosses the entire specimen. Another method proposed to generate load induced cracks is the wedge splitting method, which allows to recreate cracks on specimens with specific configuration [15]. As an alternative, cracks can be produced with the three or four-point bending procedure, typically applied to reinforced specimens [16-20]. In these cases, however, the presence of the reinforcement and the dimensions of the specimens (beam-shaped) do not allow to perform traditional chloride penetration resistance tests.

To characterize cracks, crack width $\left(w_{\mathrm{cr}}\right)$ and crack depth $\left(d_{\mathrm{cr}}\right)$ are considered as main influencing parameters. For load-induced cracks, crack width is measured either as crack mouth opening displacement (CMOD) by means of linear variable displacement transducers [9-12] or with strain gauges [17] during the cracking process, or at the end of cracking procedure observing the surface of the specimen with a microscope $[18,19]$. Most studies, concerning either artificial notches or mechanically-induced cracks, investigate on cracks widths larger than micro-crack range $\left(w_{\mathrm{cr}}>0.1 \mathrm{~mm}\right)$. The effects of micro-cracks on mass transport are investigated in works concerning drying-induced micro-cracking [22, 23], in which however an interconnected and randomly oriented crack pattern is obtained. Crack depth is always considered in studies with artificial notches, while is considered in few studies concerning load-induced cracks, typically measured on the external surface of reinforced specimens subject to three or four points bending procedures [17-19].

The Rapid Chloride Migration (RCM) test is one of the possible procedures for the rapid evaluation of chloride penetration resistance, and it is also proposed in the performance-based approaches for the design of reinforced concrete structures [24]. It relies on the application of an external voltage to accelerate chloride penetration, and measurement of the chloride penetration profile inside the specimen with a colorimetric test. In applying RCM to cracked concrete, the advantage lies in the possibility to detect how the chloride penetration front is locally altered by the presence of the crack. A limited number of studies, however, have been addressed in defining the resistance to chloride penetration of cracked concrete through RCM test. In a study on wide artificial notches (200-500 $\mu \mathrm{m}$ wide and 5-10 $\mathrm{mm}$ deep) Marsavina et al. [4] reported that the penetration of chlorides was higher from the tip of the notch than in sound (uncracked) conditions, and that it increased with increasing the notch depth, while the influence of notch width was less pronounced. Also in Li et al. [6] the chloride penetration front was studied in concrete specimens with artificial notches 50-200 $\mu$ m wide and $20 \mathrm{~mm}$ deep. It was found that the effect of the crack could be neglected for crack width smaller than $50 \mu \mathrm{m}$. Audenaert et al. [10] employed the feedbackcontrolled Brazilian splitting test on cylindrical specimens to induce cracks $0-200 \mu \mathrm{m}$ wide. In this study also micro-cracks (crack width lower than $100 \mu \mathrm{m}$ ) were considered, and it was found that the chloride penetration depth in correspondence of the crack increased linearly with crack opening until $w_{\text {cr }}$ of $100 \mu \mathrm{m}$, where a plateau seemed to be reached, equal to 10 times the penetration depth in sound conditions. In Wang et al. [20] concrete cores were extracted from larger prisms subject to compressive loading (diffuse cracking). In this case an attempt in quantifying the effects of cracks in terms of migration coefficient was carried out. Since specimens presented multiple cracking, a unique migration coefficient was evaluated considering measurements of the whole specimen sections, and the ratio between it and the migration coefficient in sound conditions was found to increase linearly with cracks frequency. Nevertheless, the evaluation of a unique migration coefficient resulted 
in underestimating the local effect of the crack, in the case of micro-cracks. Yoon and Schlangen [21], studied the influence on chloride migration coefficient of micro-cracks, induced by a tensile load. In this case, the value of migration coefficient was evaluated in correspondence of the crack, which resulted to increase linearly with the increase of crack width. Moreover, a better correlation was found considering as crack width the one measured with optical microscope at the end of the exposure test, with respect to CMOD measurements.

In summary, it is difficult to draw comparisons and conclusions from the literature on the subject due to a high inhomogeneity in the procedures adopted to crack the specimens, to define crack geometrical parameters and to evaluate chloride penetration resistance. RCM seems to be effective in detecting the effects of cracks on the resistance to chloride penetration, but few studies were conducted applying RCM to cracked concrete, in most cases with wide artificial notches, and, among them, few studies quantified the effects of cracks in terms of chloride migration coefficient. This study is part of an extensive research project currently being carried out to assess the effect of micro-cracks on chloride penetration resistance through different test methods. In this work preliminary results concerning the evaluation of the effects on micro-cracks in different types of concrete through $\mathrm{RCM}$ test are reported. Chloride penetration resistance of concrete in sound and micro-cracked configurations was evaluated, considering three different cement types, two $w / c$ ratios and two different times of curing. The micro-cracks were obtained with a specifically developed cracking procedure, in order to obtain realistic and bending-induced micro-cracks in unreinforced specimens. The results, in terms of chloride migration coefficients, were then correlated with crack geometrical parameters, i.e. crack width and crack depth, measured with a stereoscopic microscope at the end of the exposure test.

\section{Experimental procedure}

\subsection{Materials and specimens}

Six different concrete mixes were investigated, obtained with three different cement types and two different $w / c$ ratios. The cement types used were an
Ordinary Portland Cement (OPC), type CEM I 42,5R (according to EN 197-1), a Portland-Limestone cement (PLC), type CEM II/A-LL 42,5R, and a Pozzolanic Cement (PC), CEM IV/A(V) 42,5R-SR, with an amount of pozzolanic materials (in prevalence siliceous Fly Ash) between 11 and 35\%. Three concrete mixes had a $w / c$ ratio equal to 0.45 , obtained with $422 \mathrm{~kg} / \mathrm{m}^{3}$ of cement, $190 \mathrm{~kg} / \mathrm{m}^{3}$ of water and $1731 \mathrm{~kg} / \mathrm{m}^{3}$ of aggregates, while three other concrete mixes were manufactured with $w / c$ ratio equal to 0.55 , obtained with $422 \mathrm{~kg} / \mathrm{m}^{3}$ of cement, $232 \mathrm{~kg} / \mathrm{m}^{3}$ of water and $1619 \mathrm{~kg} / \mathrm{m}^{3}$ of aggregates. Crushed calcareous aggregates were used, subdivided into five grain size fractions, and characterized by a maximum diameter of $9 \mathrm{~mm}$. In order to improve workability, an acrylic-based superplasticizer was added to the mixes with $w / c$ ratio of 0.45 . Details on the mixing proportions and the concrete properties, at fresh and hardened state, are reported in Table 1.

For each concrete mix, two cubic specimens with $100 \mathrm{~mm}$ side, and eight prismatic specimens with dimensions $120 \times 90 \times 50 \mathrm{~mm}$, were cast in PVC moulds. Four prismatic specimens out of eight were provided with a V-shaped notch, around $3 \mathrm{~mm}$ deep, in the longitudinal direction on the casting surface, in order to promote the formation of a longitudinal crack during the cracking procedure (described in Sect. 2.2). Specimens were covered with a plastic film, and about $18 \mathrm{~h}$ after casting were demoulded and kept in the curing chamber, at a temperature of $20^{\circ} \mathrm{C}$ and relative humidity higher than $90 \%$. Cubic specimens were cured for 28 days and used to perform compressive strength test according to EN 12390-3 (average results from the two replicate cubic specimens are reported in Table 1). For both the $w / c$ ratios considered, OPC was the concrete type showing highest compressive strength $(76.3 \mathrm{MPa}$ and $53.6 \mathrm{MPa}$ for $w / c$ ratio of 0.45 and 0.55 respectively), followed by PC concrete (68.5 MPa and 50.5 MPa for $w / c$ ratio of 0.45 and 0.55 respectively) and PLC concrete type (63.3 $\mathrm{MPa}$ and $48.6 \mathrm{MPa}$ for $w / c$ ratio of 0.45 and 0.55 respectively). Increasing the $w / c$ ratio a decrease in compressive strength of about 30\% was observed for all the concretes obtained with the different cement types.

Half of the prismatic specimens (two sound and two cracked) were cured for 7 days, whilst the other specimens were cured for 28 days. After curing, the chloride penetration resistance was evaluated through the RCM test (described in Sect. 2.3). To refer to the 
Table 1 Mixing proportions and properties at fresh and hardened state for the different concretes

\begin{tabular}{lllllll}
\hline & OPC45 & PLC45 & PC45 & OPC55 & PLC55 & PC55 \\
\hline Cement $\left(\mathrm{kg} / \mathrm{m}^{3}\right)$ & 422 & 422 & 422 & 422 & 422 & 422 \\
Water $\left(\mathrm{kg} / \mathrm{m}^{3}\right)$ & 190 & 190 & 190 & 232 & 232 & 232 \\
Aggregate $\left(\mathrm{kg} / \mathrm{m}^{3}\right)$ & 1731 & 1731 & 1731 & 1619 & 1619 & 1619 \\
$w / c$ ratio & 0.45 & 0.45 & 0.45 & 0.55 & 0.55 & 0.55 \\
Superplasticizer $(\%$ wt. vs cem) & 0.49 & 0.42 & 0.42 & - & - & - \\
Slump $(\mathrm{mm})$ & 140 & 148 & 55 & 159 & 195 & 165 \\
Density $\left(\mathrm{kg} / \mathrm{m}^{3}\right)$ & 2451 & 2494 & 2494 & 2385 & 2422 & 2359 \\
$f_{\text {c,cube,28days }}(\mathrm{MPa})$ & 76.3 & 63.3 & 68.5 & 53.6 & 48.6 & 50.5 \\
\hline
\end{tabular}

different types of concrete, descriptive labels will be used containing information about cement type, $w / c$ ratio and time of curing (e.g. OPC45-7 for OPC cement, with $w / c$ ratio of 0.45 and tested after 7 days of curing).

\subsection{Cracking procedure}

The prismatic specimens provided with a V-shaped notch were subjected to a specifically developed cracking procedure, in order to obtain bendinginduced micro-cracks. The procedure was executed within $24 \mathrm{~h}$ after casting, to take advantage of a lower mechanical strength and a less brittle behavior of concrete, obtaining therefore a more controllable cracking process. As shown in Fig. 1, the specimens were encased in a steel confinement system and placed in a universal testing machine, with the V-shaped notch facing downwards. To reproduce a three-point bending configuration three strips, obtained with a $1.2 \mathrm{~mm}$ thick synthetic elastomer membrane, were positioned between the specimen and the testing machine, two in correspondence of the lower side (supports), parallel to the notch, and one (loading pin) centered in correspondence of the upper face (dimensions and position of rubber strips as shown in Fig. 1). The universal testing machine was set in order to induce a displacement controlled load, at constant vertical displacement equal to $0.5 \mathrm{~mm} / \mathrm{min}$. The loading procedure was set to continue until it reached a level of load $20 \%$ higher with respect to the load corresponding to the first appearance of crack on both sides of the sample. At the end of the procedure the specimens were unloaded, released from the confinement system and placed in the curing chamber. Through this loading configuration, a single V-shaped crack was expected to be obtained, starting in correspondence of the notch. The actual configuration of cracks, however, was observed at the end of the exposure test. The preparation of specimens for this purpose is described in Sect. 2.4.

\subsection{Chloride penetration resistance}

The resistance to chloride penetration of concrete was estimated through the RCM test, non-steady state migration test, in accordance to NT BUILD 492 [25]. At the end of the curing time, all the specimens were

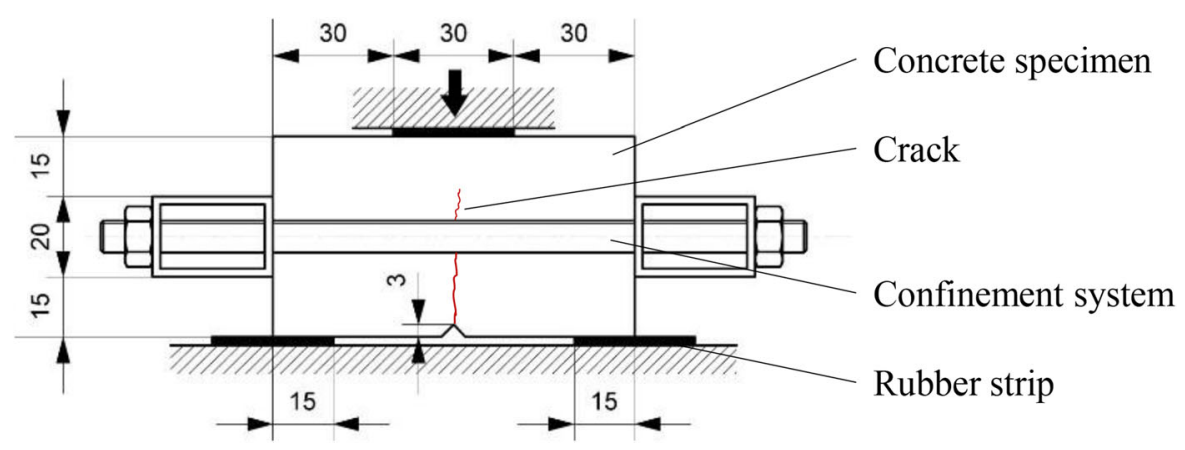

Fig. 1 Schematic representation of the cracking procedure (dimensions in $\mathrm{mm}$ )

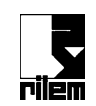


preconditioned by vacuum saturation in a $\mathrm{Ca}(\mathrm{OH})_{2}$ solution. With respect to the procedure described in the method some modifications were introduced in the preparation of the test, as a result of the different manufacturing procedure and geometry of the specimens. Preliminary tests were performed to verify that the modifications did not affect the results and more details on the validation of the experimental procedure followed in this study are reported in Russo et al. [26]. Before starting the test, the casting surface of the specimens was exposed to a catholyte solution, $10 \%$ $\mathrm{NaCl}$, while the upward face was exposed to an anolyte solution, $0.3 \mathrm{M} \mathrm{NaOH}$. Two specimens per time were connected in parallel to the same power supply, setting the voltage and the duration of the test in accordance to the method prescriptions. In particular, voltages included in the range $10-25 \mathrm{~V}$ were applied, always for a duration of $24 \mathrm{~h}$. During this period, the anolyte temperature was also monitored [25], registering a maximum increase of $1{ }^{\circ} \mathrm{C}(5 \%$ of the initial anolyte temperature).

At the end of the exposure, a colorimetric test was performed to evaluate the chloride penetration profile in concrete specimens. To this purpose, each specimen was split in two different points along the longitudinal direction, i.e. perpendicular to the crack plane for cracked configuration. A $0.1 \mathrm{M}$ silver nitrate solution was sprayed on freshly split surfaces, and the measurement of chloride penetration depth was performed. On each split surface, the measurements were performed in seven different points, i.e. the central one and at a distance of 10, 20 and $30 \mathrm{~mm}$ on each side. For cracked specimens an additional measurement was carried out, in correspondence of the maximum penetration depth. In order to exclude the influence of the notch, in the cracked specimens the measurements in correspondence of the central point and the maximum penetration depth were taken starting from the tip of the notch. Chloride penetration depth measurements were then used to evaluate the nonsteady state migration coefficient, $D_{\mathrm{RCM}}\left(\mathrm{m}^{2} / \mathrm{s}\right)$, according to the following correlation [27]:

$D_{\mathrm{RCM}}=\frac{R T}{z F E} \cdot \frac{x-\alpha \sqrt{x}}{t} \quad\left(E=\frac{U-2}{L}\right)$

where $R$ is the gas constant $(8.314 \mathrm{~J} / \mathrm{K} \mathrm{mol}), T$ is the average value of the temperatures in the anolyte solution $(\mathrm{K}), z$ is the absolute value of ion valence (1 for chloride ions), $F$ is the Faraday constant $\left(9.648 \times 10^{4} \mathrm{~J} / \mathrm{V} \mathrm{mol}\right), x$ is the average value of the penetration depth measurements $(\mathrm{m}), t$ is the duration of the test (s), $E$ is the actual potential difference across the specimen, $U$ the external applied potential between the two electrodes $(\mathrm{V}), L$ is the concrete specimen thickness (m). The $\alpha$ parameter in (1) is calculated as:

$\alpha=2 \sqrt{\frac{R T}{z F E}} \operatorname{erf}^{-1}\left(1-\frac{2 c_{d}}{c_{0}}\right)$

where $\operatorname{erf}^{-1}$ is the inverse of the error function, $c_{d}$ is the chloride concentration corresponding to the color change of silver nitrate solution $(\approx 0.07 \mathrm{~N})$ and $c_{0}$ is the chloride concentration in the catholyte solution $(\approx 2 \mathrm{~N})$.

\subsection{Evaluation of crack geometrical parameters}

The observation of the cracks was performed at the end of the RCM test, in correspondence of the split surfaces, in order to evaluate the two main crack geometrical parameters, i.e. crack width and crack depth. To this purpose, a two-component, low viscosity epoxy resin was mixed with a powdered dye and poured on the split surfaces of cracked specimens, at atmospheric pressure and room temperature. This was done both to highlight crack path, and to avoid crack modification during cutting (even if this possibility could not be completely excluded). After $24 \mathrm{~h}$, a thin slice, 2-3 $\mathrm{mm}$ thick and parallel to the split surface, was cut with a water cooled cutting saw. The cut surface was then prepared for the observation through a polishing procedure. A Wild M8 stereo microscope, equipped with a LED ring source for incident light observations and a Leica DFC290 RGB digital camera, was used to measure crack width at the exposed surface and to identify crack development and crack apex (images acquired with $1.01 \mu \mathrm{m}$ image pixel width through Leica Application Suite software, LAS v4.9). Crack width at the chloride-exposed surface, $w_{\mathrm{cr}}$, was evaluated as the average of 5-6 measurements ( $\pm 1 \mu \mathrm{m}$ estimated uncertainty) carried out in a range of about $1 \mathrm{~mm}$ from the bottom of the notch, while crack depth, $d_{\mathrm{cr}}$, was measured with a caliper, as the distance between the bottom of the notch and crack apex $( \pm 0.5 \mathrm{~mm}$ estimated uncertainty). To confirm the measurements of the two main 
geometrical parameters, selected slices were also observed with scanning electron microscope (SEM).

\section{Results}

\subsection{Chloride penetration resistance}

The measurements in terms of chloride penetration depths were firstly carried out. As an example, Fig. 2a shows as an example the splitting surface of a cracked OPC45-28 specimen after the spray of the silver nitrate solution, while the chloride penetration depths concerning all the four OPC45-28 specimens, in both cracked and sound configurations, are reported in Fig. $2 b$ (four splitting surfaces on each of the two

(a)

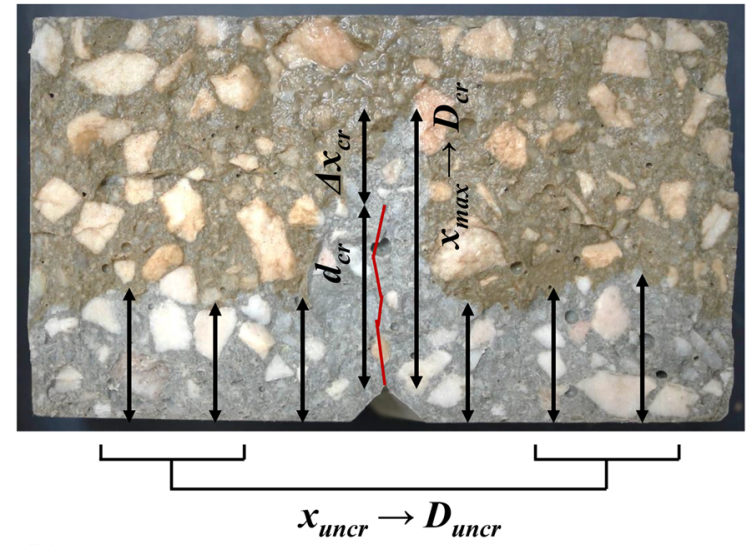

(b)

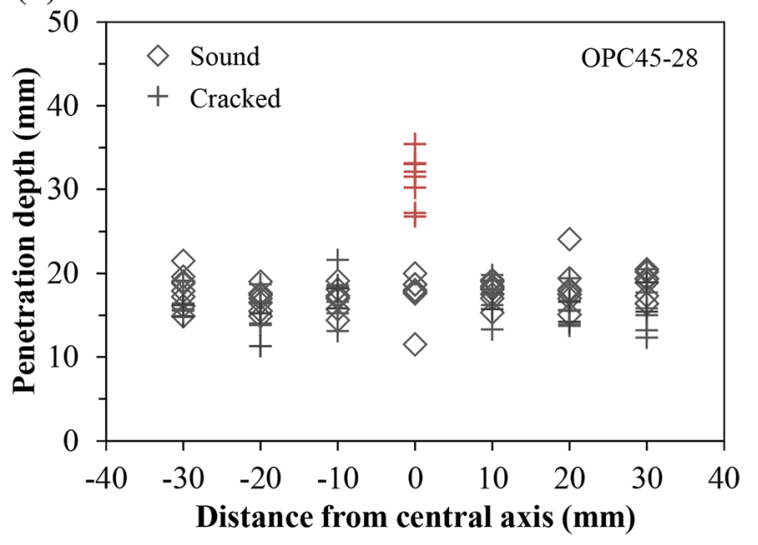

Fig. 2 a Example of colorimetric test result on an OPC45-28 cracked specimen; $\mathbf{b}$ chloride depth measurements in all sound and cracked OPC45-28 specimens ( + symbols in position $x=0$ represents maximum penetration depth in correspondence of the crack) replicate specimens, for each configuration). It can be observed that chloride penetration depths in sound configuration were quite consistent with the measurements carried out in cracked configuration, at distance equal or higher than $10 \mathrm{~mm}$ from the central axis, while the chloride penetration depths in correspondence of the crack showed a significant increase. As previously described (Sect. 2.3), the measurements in this case were carried out excluding the influence of the notch, therefore the chloride penetration depth increment was exclusively attributed to the presence of the crack. The measurements of chloride penetration depths were used to evaluate $D_{\mathrm{RCM}}$. In sound configuration, $D_{\mathrm{RCM}}$ was evaluated considering the average chloride penetration depth on the whole split surface $\left(D_{\mathrm{s}}\right)$. In cracked configuration a value of $D_{\mathrm{RCM}}$ in correspondence of the crack was evaluated $\left(D_{\mathrm{cr}}\right)$ considering the maximum chloride penetration depth $\left(x_{\max }\right)$ measured in correspondence of the crack (in red in Fig. 2b), whereas a value of $D_{\mathrm{RCM}}$ in the uncracked part of the specimen, considering measurements at \pm 20 and $\pm 30 \mathrm{~mm}$ from the central axis was also evaluated $\left(D_{\text {uncr }}\right)$.

The results obtained for the different concrete types and different curing times are reported in Fig. 3, where error bars represent maximum and minimum values. After 7 days of moist curing, in sound configuration, OPC concretes showed diffusion coefficient $D_{\mathrm{RCM}}$ equal to $16 \times 10^{-12} \mathrm{~m}^{2} / \mathrm{s}$ for OPC45, and $24 \times 10^{-12}$ $\mathrm{m}^{2} / \mathrm{s}$ for OPC55. PLC concretes showed $D_{\mathrm{RCM}}$ equal to $23 \times 10^{-12} \mathrm{~m}^{2} / \mathrm{s}$ for PLC45, and $28 \times 10^{-12} \mathrm{~m}^{2} / \mathrm{s}$ for PLC55 and PC type showed $D_{\mathrm{RCM}}$ values equal to $28 \times 10^{-12} \mathrm{~m}^{2} / \mathrm{s}$ for PC45 and $30 \times 10^{-12} \mathrm{~m}^{2} / \mathrm{s}$ for PC55. The same concrete types tested after 28 days of curing experienced a general decrease in the chloride migration coefficient; for instance, $D_{\mathrm{RCM}}$ of the OPC concrete decreased to $10 \times 10^{-12} \mathrm{~m}^{2} / \mathrm{s}$ for OPC45, and $21 \times 10^{-12} \mathrm{~m}^{2} / \mathrm{s}$ for OPC55. Results obtained on OPC are comparable with values reported in [24].

It is worth noting that concrete is a highly heterogeneous material, and consequently the chloride penetration is strongly dependent on local features, such as the presence of aggregates. This is evident also in the measurements of chloride penetration depth on the single split surfaces of sound samples (Fig. 2b) that indicates a high and very variable relative standard deviation (from 3 to $23 \%$, depending on the specific analyzed surface). This intrinsically limits the precision of chloride migration quantification in 


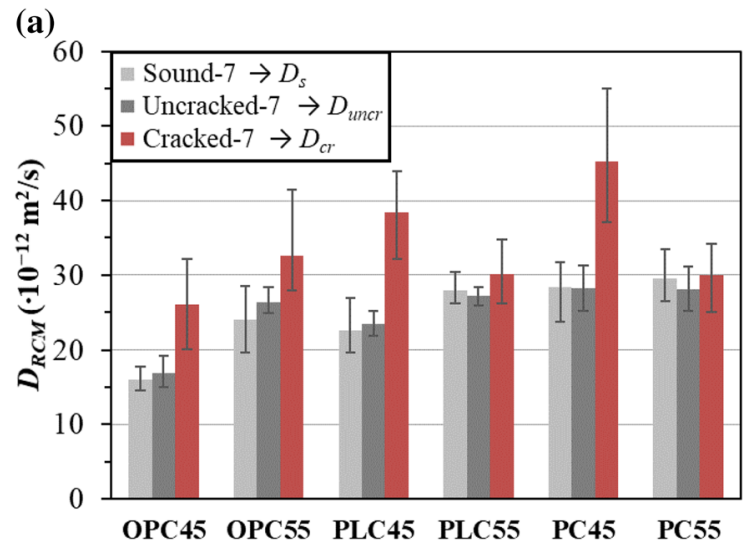

(b)

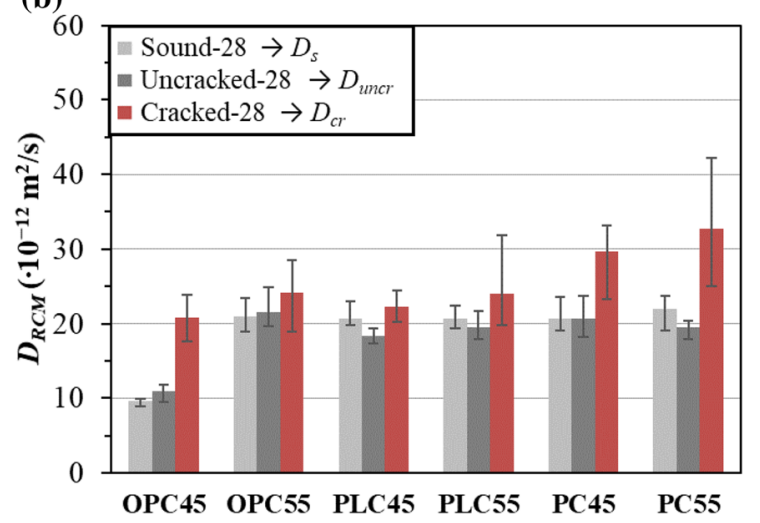

Fig. 3 Average value and variability of chloride migration coefficients evaluated in sound and cracked configurations, for different concrete types at $\mathbf{a} 7$ days and $\mathbf{b} 28$ days of curing

concrete samples and, specifically, with the described method. The derived $D_{\mathrm{RCM}}$ data can be also influenced, for cracked samples, by the high heterogeneity of geometrical properties of induced cracks (e.g. width, depth and pattern). Moreover, while the $D_{\mathrm{RCM}}$ values computed for sound samples and the uncracked part of cracked samples ( $D_{\mathrm{s}}$ and $D_{\text {uncr }}$ respectively) can benefit from multiple $x$ value measurements for each splitting surface, only one $x$ value per surface is available for measurements of $D_{\mathrm{RCM}}$ in the crack $\left(D_{\mathrm{cr}}\right)$. This is reflected in the higher dispersion of final $D_{\text {cr }}$ values with respect to $D_{\text {s }}$ and $D_{\text {uncr }}$ results (Fig. 3).

The increase in $w / c$ ratio resulted, as expected, in a general increase in chloride migration coefficient, which is the inverse of resistance to chloride penetration resistance of concrete. For concrete tested after 7 days of curing, this effect resulted more pronounced for OPC and PLC types, showing an increase in $D_{\mathrm{RCM}}$ of $50 \%$ and $24 \%$ respectively, and less pronounced for
PC type, with a decrease in $D_{\mathrm{RCM}}$ of about $4 \%$. For $D_{\mathrm{RCM}}$ evaluated after 28 days of moist curing, OPC showed an even more marked increase, about $118 \%$, while PC type still showed a limited increase, about $6 \%$.

As it concerns the cracked specimens, it can be observed that the chloride penetration resistance evaluated in the uncracked zone of the specimens, i.e. at a distance of $\pm 20 \mathrm{~mm}$ and $\pm 30 \mathrm{~mm}$ from the crack, was comparable to that obtained in sound conditions. This result suggested that in the case of cracked specimens no significant redistribution of current occurred due to the presence of the notch and the micro-crack. In correspondence of the microcrack, a local increase in chloride migration coefficient with respect to sound configuration occurred, in all the cases considered. In particular, the increase in average $D_{\mathrm{RCM}}$ in correspondence of the crack resulted more pronounced for all the concrete types with $w / c$ ratio of 0.45 and at 7 days of moist curing, equal to $63 \%$ for OPC, $70 \%$ for PLC and $60 \%$ for PC type. The same concrete types after 28 days of moist curing, instead, showed an increase in $D_{\mathrm{RCM}}$ in the crack equal to $116 \%, 8 \%$ and $44 \%$, respectively, with respect to sound conditions. Furthermore, an increase in the variability of results was clearly detected, when considering results obtained in correspondence of the crack. However, it should be taken into account that cracks in different specimens can be characterized by different geometrical parameters. For this reason, the characterization of cracks was performed, at the end of the exposure test, in order to identify the two main crack geometrical parameters in correspondence of the split surfaces, where chloride penetration was previously evaluated.

\subsection{Characterization of cracks}

The observation of cracks at the stereomicroscope highlighted the presence of several different crack patterns. The main categories of crack opening (CO) and crack development (CD) are schematically represented in Fig. 4. Four different categories of $\mathrm{CO}$ were detected, identified through letters:

A. single crack opening, clearly detectable, in correspondence of the bottom of the notch;

B. single crack opening, clearly detectable, completely outside the notch; 


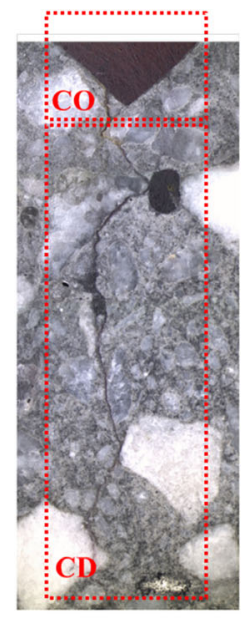

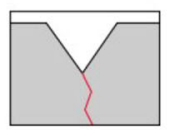
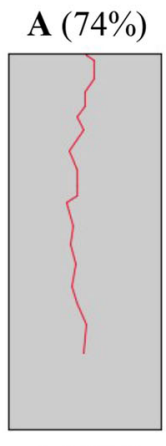

$1(72 \%)$
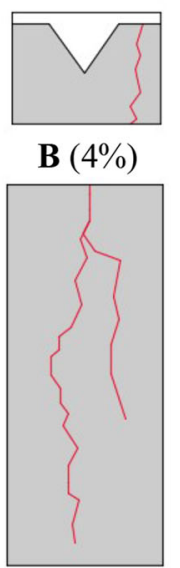

$2(6 \%)$
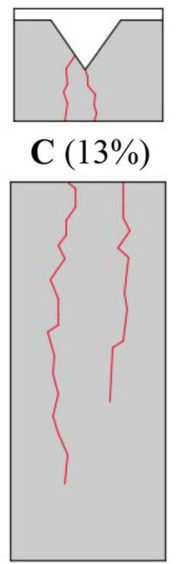

$3(3 \%)$

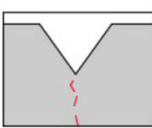

D $(9 \%)$

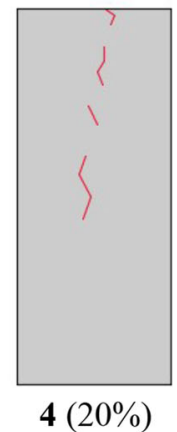

Fig. 4 Example of crack observed at the stereomicroscope and different categories of crack opening (CO) and crack development (CD), with their frequency with respect to the total of analyzed samples

C. two distinct crack openings, both in correspondence of the notch or in the immediate vicinity;

D. single crack opening, not clearly visible, due to the narrow width or due to discontinuities in the crack path.

With regard to the $\mathrm{CD}$, four categories were detected and identified with numbers:

1. single crack path, clearly detectable;

2. from an initial single path the crack developed in two distinct branches, both wider than $10 \mu \mathrm{m}$;

3. two distinct crack paths developed from two distinct crack openings at the exposed surface;

4. single crack development, not clearly visible, due to the narrow width, smaller than about $5 \mu \mathrm{m}$.

In Fig. 4 the respective frequencies of $\mathrm{CO}$ and $\mathrm{CD}$ (as percentage with respect to the 90 analyzed samples) are indicated. Among the different combinations between $\mathrm{CO}$ and $\mathrm{CD}$, the crack typology $\mathrm{A} 1$ resulted by far the most common one, representing the $63 \%$ of all examined cracks, followed by categories A4 and D4 (both equal to 9\%) and C1 (6\%). Any other combination resulted to have a frequency lower than $3 \%$ of the total.

The results obtained in terms of crack width $w_{\mathrm{cr}}$ and crack depth $d_{\text {cr }}$ for different concrete types and different curing times are reported in Fig. 5 (in the case of multiple crack openings, or double crack

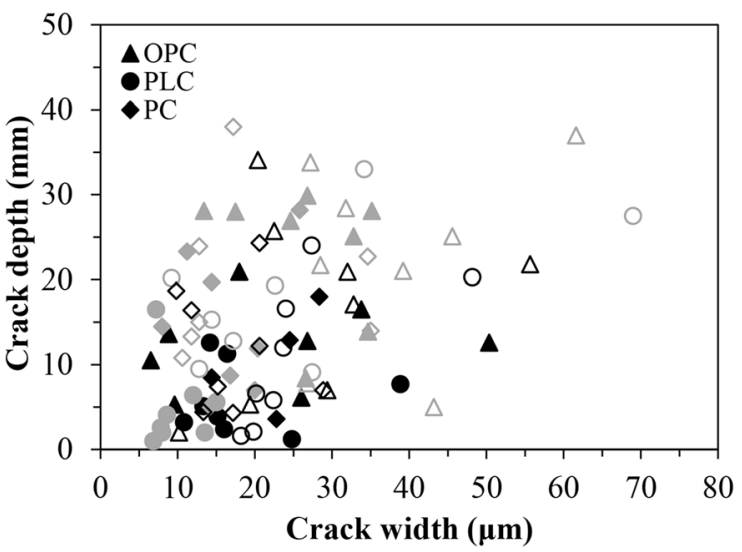

Fig. 5 Crack width as a function of crack depth, light and dark symbols representing $w / c$ ratio of 0.45 and 0.55 , respectively, and empty and filled symbols representing 7 and 28 days cured specimens, respectively

branches the measurements refer to the main and bigger one).

Crack widths resulted mainly included in the range 5-70 $\mu \mathrm{m}$, while crack depth were mainly included in the range $1-40 \mathrm{~mm}$. Crack width measurements showed a quite high variability of the width profile (the average value of relative standard deviation of width measurements was about $30 \%$ ). Considering that each crack width evaluation was obtained as a mean of 5-6 measurements, and that a normal distribution of data could not be supposed, a relative 
average uncertainty of the final crack width values of $15 \%$ was estimated.

Data seemed to follow an increasing trend, even if it was not possible to find a clear correlation between $w_{\mathrm{cr}}$ and $d_{\mathrm{cr}}$. The variability of crack parameters resulted quite high both considering the two replicate specimens, and even considering the measurements carried out in different points of the same specimen.

The observation of selected specimens carried out with SEM confirmed that the measurements of crack opening $\left(w_{\mathrm{cr}}\right)$ were on average characterized by a precision of about $5 \mu \mathrm{m}$, while confirmed the crack apex detected with stereomicroscope for the measurements of crack depth. The SEM observation also revealed a further characteristic of cracks, concerning the inhomogeneity of crack width along crack path. With the stereoscopic microscope it was previously observed that in the majority of samples, regardless the CD category, crack path seemed to be interrupted in different points. The analyses carried out with SEM confirmed that in those points a sharp narrowing of the crack width occurred along crack path, as shown in Fig. 6, which could however be due to mechanical actions occurred after the exposure test (splitting and slicing).

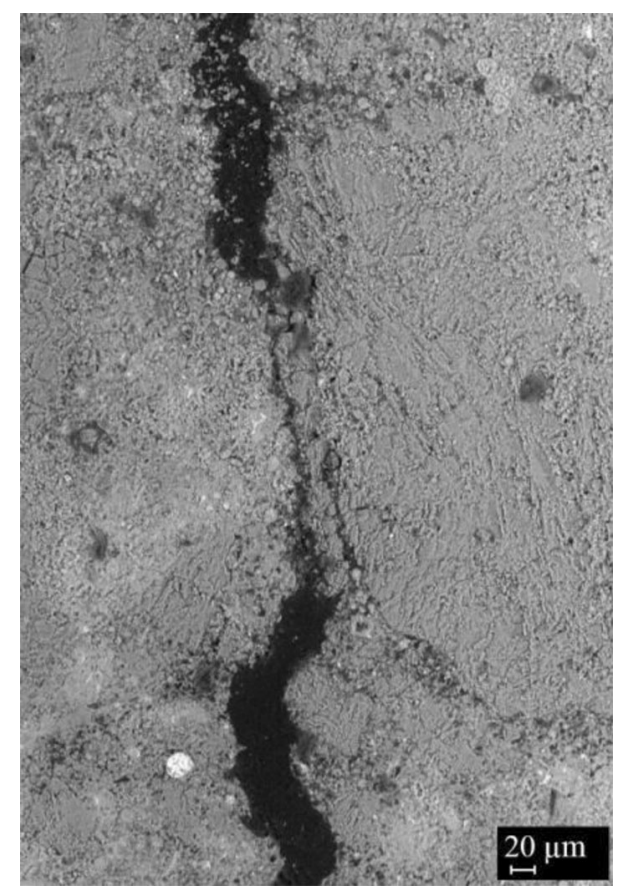

Fig. 6 Significant reduction of crack width along the crack path, image obtained with SEM

\section{Discussion}

4.1 Effects of concrete type and curing time on $D_{\mathrm{RCM}}$

The results obtained on sound specimens are preliminary discussed to define the effects of cement type, $w / c$ ratio and curing time on chloride penetration resistance of concrete evaluated with Rapid Chloride Migration test. Figure 7 shows the chloride migration coefficient evaluated in sound specimens, for different concrete types, as a function of curing time.

As expected, an increase in the $w / c$ ratio corresponded to an increase in chloride migration coefficient, for all the cement types considered. This is attributed to the related increase of the concrete porosity, which negatively impacts on the concrete resistance to chloride penetration. In particular, for OPC and PC concrete types, the rise of $D_{\mathrm{RCM}}$ with increasing the $w / c$ ratio resulted more marked when concretes were tested after 28 days of curing.

Independently from the $w / c$ ratio considered, the concrete type showing the lower $D_{\mathrm{RCM}}$ was the one obtained with Ordinary Portland Cement, followed by Portland-Limestone Cement and Pozzolanic Cement. However, the long-term chloride penetration resistance of PC concrete type, is probably underestimated. The results of compressive strength test showed that PLC and PC concrete type were quite similar after 28 days of curing, and this means that the porosity of the two concretes at that hardening stage were comparable. The resistance to chloride penetration,

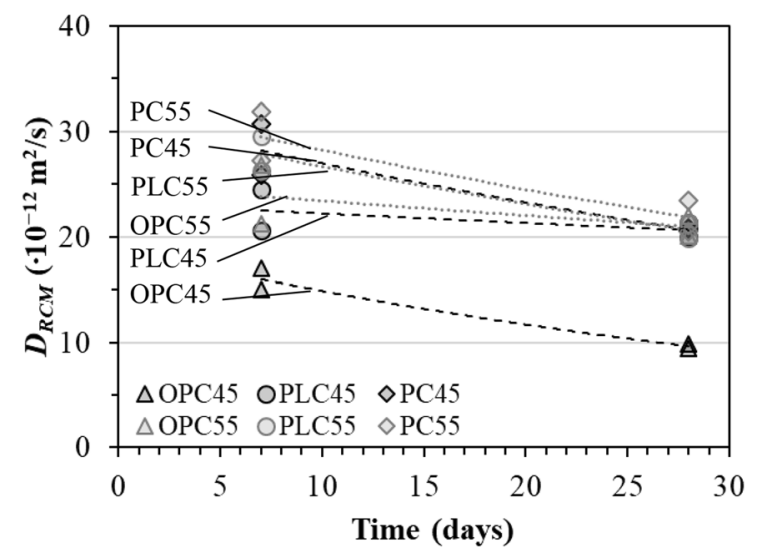

Fig. 7 Chloride migration coefficient evaluated in sound specimens, for different concrete types, as a function of curing time 
however, is more affected by pore microstructure, and concrete made with pozzolanic cements require more prolonged curing times to develop a more defined porous microstructure. Pore microstructure refinement, due to the further hydration of the cement, is considered one of the main controlling parameters of transport properties in concrete [1]. In a study carried out by Andrade et al. [28] it is reported that the total porosity of a concrete containing Fly Ash experienced a decrease of about $36 \%$ when the curing increased from 28 days to one year, while for OPC concrete no significant differences were observed at the two different times of curing, meaning that the process of pore refinement for this concrete was essentially concluded within the 28 days of curing. This effect of further hydration of cement particles, the so called ageing effect, occurs particularly during the exposure of concrete to a solution for prolonged exposure times.

With accelerated testing procedures, such as the RCM test, it is not possible to account for the ageing effect. Some insight can be obtained however by testing specimens at different times of curing, allowing the concrete samples to refine the porous microstructure and therefore develop a higher resistance to chloride penetration. In this study two sets of specimens were evaluated after 7 and 28 days of moist curing respectively. In Fig. 7 the decrease of $D_{\mathrm{RCM}}$ in time is interpolated through exponential curves, lighter for concrete types with $w / c$ ratio of 0.45 and darker for concrete types with $w / c$ ratio of 0.55 . The Pozzolanic concrete type experienced a decrease in $D_{\mathrm{RCM}}$ of about $27 \%$ at both the $w / c$ ratio, confirming the effect of the pore refinement for this concrete type for longer moist curing times. As it concerns Portland and Portland-limestone concretes, a more variable decrease in $D_{\mathrm{RCM}}$ was found, between 9 and $40 \%$, depending on the $w / c$ ratio.

\subsection{Effects of crack width and depth on chloride penetration}

The local increase in $D_{\mathrm{RCM}}$ in correspondence of the crack was evaluated as the ratio between the migration coefficient in correspondence of the crack $\left(D_{\mathrm{cr}}\right)$ and in sound conditions $\left(D_{\mathrm{s}}\right)$. For the evaluation of $D_{\mathrm{cr}}$, in this analysis, only samples containing one single crack starting in correspondence of the notch were considered (typologies A1, A4 and D4). Figure 8 shows results obtained, as a function of crack width and crack

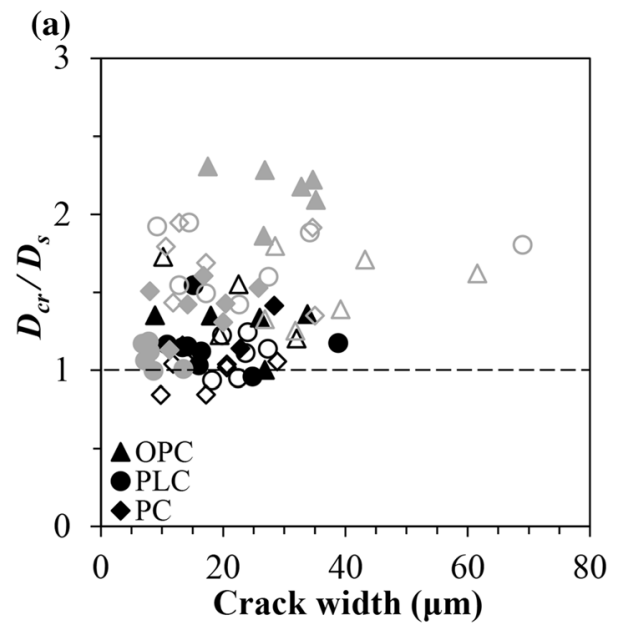

(b)

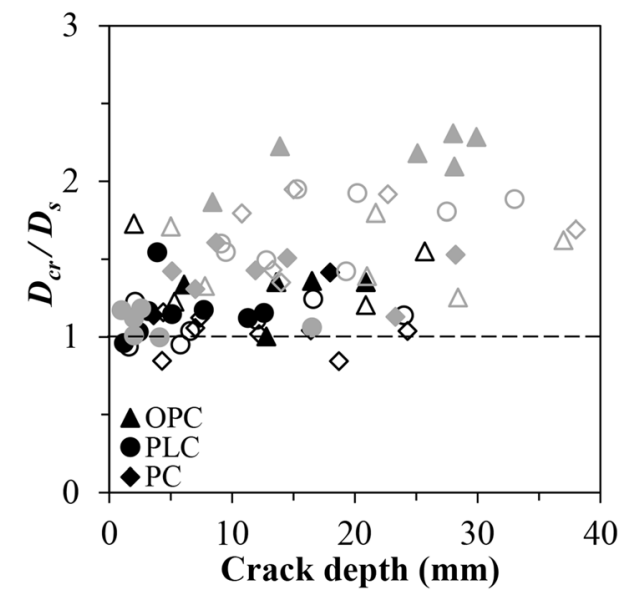

Fig. 8 Local increase in $D_{\mathrm{RCM}}$, evaluated as the ratio between $D_{\text {cr }}$ and $D_{\mathrm{s}}$, in correspondence of the crack, as a function of a crack width and b crack depth; light and dark symbols representing $w / c$ ratio of 0.45 and 0.55 , respectively, and empty and filled symbols representing 7 and 28 days cured specimens, respectively

depth, for the different concrete types considered, after 7 days of curing and after 28 days of curing. Considering the results for concretes with $w / c$ ratio of 0.45 after 7 days of curing (empty symbols in Fig. 8a, b) it can be observed that independently from the concrete type the migration coefficient in the crack resulted, in most cases, from 1.5 to 2 times higher the value in sound conditions, for crack widths up to $70 \mu \mathrm{m}$ and crack depths up to $37 \mathrm{~mm}$. For comparable crack geometrical parameters, the effect of the crack in concretes with $w / c$ ratio of 0.55 resulted less pronounced, with values of $D_{\mathrm{cr}} / D_{\mathrm{s}}$ mostly around 1 . Considering results after 28 days of curing (filled 
symbols in Fig. 8a, b) the $D_{\mathrm{cr}} / D_{\mathrm{s}}$ values resulted around 1 for Portland-Limestone concretes at both the $w / c$ ratios. This is however consistent with the crack geometrical parameters, since all these specimens were characterized by narrow and shallow cracks. For Portland and Pozzolanic concretes $D_{\mathrm{cr}} / D_{\mathrm{s}}$ resulted slightly higher, mostly around 1.5 , but showed a markedly higher increase in the case of OPC samples with $w / c$ ratio of 0.45 , with values higher than 2 . For these concretes, indeed, even if values of crack width were comparable, the crack depths were more pronounced, with respect to the PC samples. Furthermore, no clear effects of different concrete types were detected, except that the value of $D_{\mathrm{cr}} / D_{\mathrm{s}}$ was particularly higher for OPC45-28, which was the more impervious concrete considered. This was probably due to a combination of reasons, including that OPC45 was the concrete with highest mechanical strength (highest elastic modulus, more brittle) and therefore developed deepest cracks (Fig. 5) and that OPC was characterized by very low permeability in sound configuration.

From the results of this study it was observed that load-induced micro-cracks, 5-70 $\mu \mathrm{m}$ wide, were able to affect the chloride penetration-and therefore the chloride migration coefficient-in the crack, conversely to what was obtained in literature on specimens with artificial notches [6]. However, a clear correlation between $D_{\mathrm{cr}} / D_{\mathrm{s}}$ and crack width alone could not be defined, possibly because of the relatively narrow range of studied crack widths and the high data scatter. This latter was due to several factors that added up, including the intrinsic heterogeneity of concrete structure that limited the $D_{\mathrm{RCM}}$ measurement accuracy (Sect. 3.1), the high variability of developed crack pattern within the same specimen and the local feature of the crack (including the sharp narrowing observed with the SEM). Nevertheless, even if most of the studies in literature concerning load-induced cracks consider only crack width in correspondence of the exposed surface, the results obtained in this study suggested that both parameters should be considered. Moreover, instead of considering the two parameters independently, a useful investigation could be carried out on the combined effect crack widthcrack depth in evaluating the increase in chloride penetration with respect to sound conditions. In order to draw preliminary considerations on the combined effect of crack width and crack depth, Fig. 9 shows

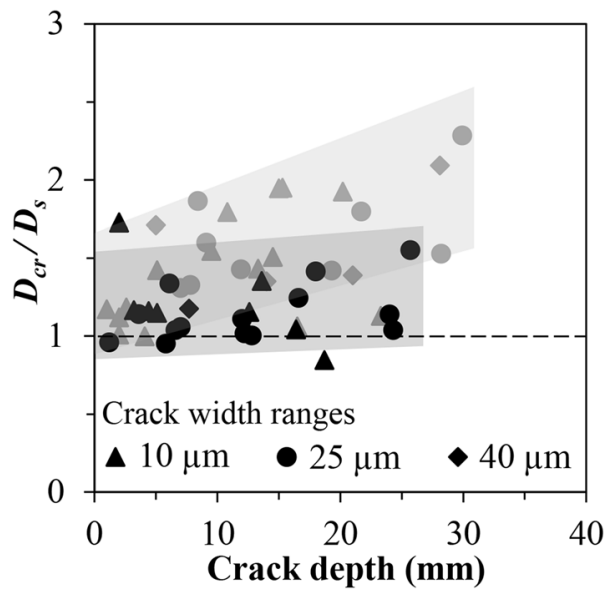

Fig. 9 Local increase in $D_{\mathrm{RCM}}$, evaluated as the ratio between $D_{\text {cr }}$ and $D_{\mathrm{s}}$, in correspondence of the crack, as a function of crack depth and for different ranges of crack width; light and dark symbols and areas representing $w / c$ ratio of 0.45 and 0.55 , respectively

results in terms of $D_{\mathrm{cr}} / D_{\mathrm{s}}$, where data were grouped for different ranges of crack width, neglecting the cement type and curing time. It can be observed, despite the high scatter of data, that for cracks characterized by comparable widths at the exposed surface, the increase in chloride migration coefficient in the crack is not constant but increases with the increase in crack depth. Also in this case a clear correlation could not be found, but the trend of data suggested that the ratio $D_{\mathrm{cr}} / D_{\mathrm{s}}$ increased with increasing crack depth, and that the increment was higher for concretes with lower $w / c$ ratio with respect to higher ones (lighter and darker areas in Fig. 9, respectively) and was independent from the crack width at the exposed surface.

It is worth to notice, however, that in correspondence of the crack a unique value of $D_{\text {cr }}$ was evaluated, not considering that chloride penetration may vary inside the crack and after crack apex. A further analysis was then carried out, in order to correlate the additional penetration depth from the tip of the crack and the penetration depth in the uncracked part of the specimen ( $\Delta x_{\mathrm{cr}}$ and $x_{\mathrm{uncr}}$ in Fig. 2a, respectively) with the geometrical parameters of the crack (Fig. 10). When considering the difference $\Delta x_{\mathrm{cr}}-x_{\text {uncr }}$ (reported on y axis) three cases can occur:

1. $\Delta x_{\mathrm{cr}}-x_{\mathrm{uncr}}=0$ Same chloride penetration depth in the uncracked part of the specimen than from the apex of the crack. In this case the crack may 

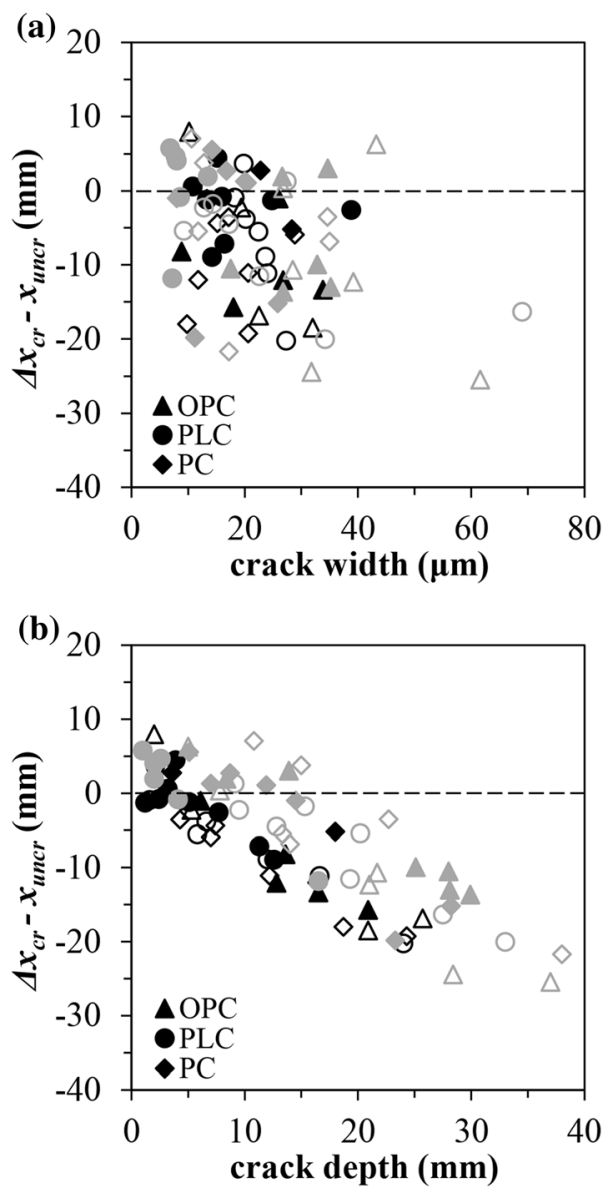

Fig. 10 Difference between the additional penetration depth in the crack and the penetration depth in uncracked conditions $\left(\Delta x_{\mathrm{cr}}-x_{\mathrm{uncr}}\right)$ as a function of $\mathbf{a}$ crack width and $\mathbf{b}$ crack depth; filled and empty symbols representing 7 and 28 days cured specimens, respectively; light and dark symbols representing $w / c$ ratio of 0.45 and 0.55 , respectively

not have offered any resistance to chloride penetration.

2. $\Delta x_{\mathrm{cr}}-x_{\text {uncr }}>0$ Chlorides penetrated more from crack apex than in the uncracked part (probably due to a higher concentration of current in correspondence of the crack or due to variability of results).

3. $\Delta x_{\mathrm{cr}}-x_{\mathrm{uncr}}<0$ Chloride penetration from crack apex was less pronounced than in the uncracked part of the specimen. In this case the crack may have contributed to chloride penetration resistance.

From Fig. 10 it can be observed that most of the measurements related to the latter case. $\Delta x_{\mathrm{cr}}-x_{\text {uncr }}$ seemed to be not correlated with crack width, while it decreased constantly with increasing crack depth. This suggested that the crack offered a resistance to chloride penetration which was directly proportional to crack depth, and therefore that in correspondence of the crack two different chloride migration coefficients should be considered, one until crack apex, and the migration coefficient in the sound concrete from the apex of the crack. However, the colorimetric method does not easily allow to evaluate the two different migration coefficients.

Moreover, it seemed that until crack apex the migration coefficient was not affected by the cement type and concrete curing time, while it may have been affected by $w / c$ ratio. In Fig. 10b, in fact, it seems that for same crack depth concretes made with $w / c$ of 0.45 (light symbols) showed less negative values of $\Delta x_{\text {cr }}-x_{\text {uncr }}$, meaning that the effect of chloride penetration resistance in the crack was less pronounced than in concretes made with $w / c$ ratio of 0.55 . This result may further confirm what was previously stated, i.e. it seemed that the presence of a micro-crack had more pronounced effects in more impervious concretes, in agreement with other experimental [15] and numerical [29] studies.

The RCM test, however, is an accelerated testing procedure based on the imposition of an electrical voltage, which may not be representative of chloride transport in real RC structures, and whose results may be affected by the distribution of the electrical current in the specimen, especially in presence of cracks. At this regard, an experimental plan has been developed [30] to evaluate the effects of micro-cracks in concrete specimens subject to pure diffusion under long-term testing, which will also allow to account for possible self-healing effects in the crack. In addition, further investigations will be carried out in order to decouple the chloride penetration resistance in the crack and beyond crack apex.

\section{Conclusions}

In this work the effects of micro-cracks on chloride penetration resistance of different concrete types have been evaluated, considering an Ordinary Portland, a Portland-Limestone and a Pozzolanic cement, two different $w / c$ ratios and two curing times. On the basis 
of the experimental results, the following conclusions can be outlined.

1. The mechanical loading procedure developed for the study was able to induce natural micro-cracks in prismatic specimens, characterized by a crack width included in the range 5-70 $\mu \mathrm{m}$ and crack depth between 1 and $40 \mathrm{~mm}$. The two geometrical parameters, crack width and crack depth, resulted characterized by a high variability, even within the same specimen. The observation of selected samples with SEM revealed that cracks were often characterized by sharp narrowing of the crack width along crack path.

2. From results on sound specimens, independently from the $w / c$ ratio considered, the concrete type showing higher chloride penetration resistance was the one obtained with Ordinary Portland cement, followed by Portland-Limestone cement and Pozzolanic cement. The unexpected results obtained on Pozzolanic concrete suggested that probably the RCM, performed after 7 and 28 days of curing, underestimates the PC long-term performances, since for this concrete type an increase in pore microstructure definition occurs also at prolonged curing times. A decrease, depending on the type of cement, of $D_{\mathrm{RCM}}$ was observed increasing the curing time.

3. The presence of a micro-crack resulted in a local increase in the migration coefficient, estimated as the ratio between the migration coefficient in the crack and in sound conditions $\left(D_{\mathrm{cr}} / D_{\mathrm{s}}\right)$. After 7 days of curing, in most cases $D_{\mathrm{cr}} / D_{\mathrm{s}}$ was included in the range 1.5-2 for concretes made with $w / c$ ratio of 0.45 , independently from crack geometrical parameters and concrete type. For comparable crack parameters, and considering more permeable concretes ( $w / c$ ratio of 0.55$)$, the effect resulted less pronounced, with $D_{\mathrm{cr}} / D_{\mathrm{s}}$ mostly around 1 . For concretes tested after 28 days of curing, $D_{\mathrm{cr}} / D_{\mathrm{s}}$ resulted negligible for Portland-Limestone concrete at both the $w / c$ ratios considered, but this was however consistent with the features of cracks, characterized by narrow width $(5-20 \mu \mathrm{m})$ and shallow depths $(1-15 \mathrm{~mm})$. For Pozzolanic concrete $D_{\mathrm{cr}} / D_{\mathrm{s}}$ resulted slightly higher, mostly around 1.5 for cracks $10-30 \mu \mathrm{m}$ wide and 5-30 $\mathrm{mm}$ deep. The most impermeable concrete (Ordinary Portland with $w / c$ ratio of 0.45 ) showed values of $D_{\mathrm{cr}} / D_{\mathrm{s}}$ included in the range 2-2.5 for crack widths comparable to those of Pozzolanic concrete type $(20-35 \mu \mathrm{m})$, but more pronounced crack depths (25-30 mm).

4. For the narrow ranges of crack opening and crack depth considered in this study, no correlation evidences were demonstrated between the local increase in chloride migration coefficient in the crack and crack geometrical parameters considered. On the other hand, some considerations on the additional penetration depth from crack apex suggested that the crack offers a resistance to chloride penetration which is directly proportional to crack depth. Resistance to chloride penetration in the crack resulted independent from the cement type and concrete curing time considered, while may be affected by the $w / c$ ratio, being lower for more impervious concretes.

Funding Open access funding provided by Politecnico di Milano within the CRUI-CARE Agreement.

\section{Compliance with ethical standards}

Conflict of interest The authors of this work declare that they have no conflict of interest.

Open Access This article is licensed under a Creative Commons Attribution 4.0 International License, which permits use, sharing, adaptation, distribution and reproduction in any medium or format, as long as you give appropriate credit to the original author(s) and the source, provide a link to the Creative Commons licence, and indicate if changes were made. The images or other third party material in this article are included in the article's Creative Commons licence, unless indicated otherwise in a credit line to the material. If material is not included in the article's Creative Commons licence and your intended use is not permitted by statutory regulation or exceeds the permitted use, you will need to obtain permission directly from the copyright holder. To view a copy of this licence, visit http://creativecommons.org/licenses/by/4.0/.

\section{References}

1. Bertolini L, Elsener B, Pedeferri P, Redaelli E, Polder R (2013) Corrosion of steel in concrete: prevention, diagnosis, repair, 2nd edn. Wiley VCH, Weinheim

2. ACI Committee 201 (2016) ACI 201.2R-16 guide to durable concrete. American Concrete Institute, Indianapolis

3. Boschmann Käthler AC, Angst UM, Wagner M, Larsen CK, Elsener B (2017) Effect of cracks on chloride induced corrosion of steel in concrete-a review. NPRA reports Norwegian Public Roads Administration, Oslo 
4. Marsavina L, Audenaert K, Schutter G, Faur N, Marsavina D (2009) Experimental and numerical determination of the chloride penetration in cracked concrete. Constr Build Mater 23:264-274. https://doi.org/10.1016/j.conbuildmat. 2007.12.015

5. Mu S, De Schutter G, Ma BG (2013) Non-steady state chloride diffusion in concrete with different crack densities. Mater Struct 46(1-2):123-133. https://doi.org/10.1617/ s11527-012-9888-0

6. Li Y, Chen X, Jin L, Zhang R (2016) Experimental and numerical study on chloride transmission in cracked concrete. Constr Build Mater 127:425-435. https://doi.org/10. 1016/j.conbuildmat.2016.10.044

7. Sosdean C, Marsavina L, De Schutter G (2016) Experimental and numerical determination of the chloride penetration in cracked mortar specimens. Eur J Environ Civ Eng 20(2):231-249. https://doi.org/10.1080/19648189.2015. 1035802

8. Aldea CM, Shah SP, Karr A (1999) Effect of cracking on water and chloride permeability of concrete. J Mater Civil Eng 11(3):181-187. https://doi.org/10.1061/(ASCE)08991561(1999)11:3(181)

9. Djerbi A, Bonnet S, Khelidj A, Baroghel-Bouny V (2008) Influence of traversing crack on chloride diffusion into concrete. Cem Concr Res 38(6):877-883. https://doi.org/10. 1016/j.cemconres.2007.10.007

10. Audenaert K, De Schutter G, Marsavina L (2009) Influence of cracks and crack width on penetration depth of chlorides in concrete. Eur J Environ Civ Eng 13(5):561-572. https:// doi.org/10.1080/19648189.2009.9693134

11. Jang SY, Kim BS, Oh BH (2011) Effect of crack width on chloride diffusion coefficients of concrete by steady-state migration tests. Cem Concr Res 41(1):9-19. https://doi.org/ 10.1016/j.cemconres.2010.08.018

12. Park SS, Kwon SJ, Jung SH (2012) Analysis technique for chloride penetration in cracked concrete using equivalent diffusion and permeation. Constr Build Mater 29:183-192. https://doi.org/10.1016/j.conbuildmat.2011.09.019

13. Wang J (2017) Steady-state chloride diffusion coefficient and chloride migration coefficient of cracks in concrete. J Mater Civ Eng 29(9):04017117. https://doi.org/10.1061/ (ASCE)MT.1943-5533.0001966

14. Ismail M, Toumi A, Francois R, Gagne R (2008) Effect of crack opening on the local diffusion of chloride in cracked mortar samples. Cem Concr Res 38(8):1106-1111. https:// doi.org/10.1016/j.cemconres.2008.03.009

15. Weiss J, Couch J, Pease B, Laugesen P, Geiker M (2017) Influence of mechanically induced cracking on chloride ingress in concrete. J Mater Civ Eng 29(9):04017128. https://doi.org/10.1061/(ASCE)MT.1943-5533.0001922

16. Gowripalan N, Sirivivatnanon V, Lim CC (2000) Chloride diffusivity of concrete cracked in flexure. Cem Concr Res 30(5):725-730. https://doi.org/10.1016/S00088846(00)00216-7

17. Win PP, Watanabe M, Machida A (2004) Penetration profile of chloride ion in cracked reinforced concrete. Cem Concr Res 34(7):1073-1079

18. Kato E, Kato Y, Uomoto T (2005) Development of simulation model of chloride ion transportation in cracked concrete. J Adv Concr Technol 3(1):85-94. https://doi.org/ $10.3151 /$ jact. 3.85

19. Şahmaran M (2007) Effect of flexure induced transverse crack and self-healing on chloride diffusivity of reinforced mortar. J Mater Sci 42:9131-9136. https://doi.org/10.1007/ s10853-007-1932-Z

20. Wang HL, Dai JG, Sun XY, Zhang XL (2016) Characteristics of concrete cracks and their influence on chloride penetration. Constr Build Mater 107:216-225. https://doi. org/10.1016/j.conbuildmat.2016.01.002

21. Yoon IS, Schlangen E (2014) Experimental examination on chloride penetration through micro-crack in concrete. KSCE J Civ Eng 18(1):188-198. https://doi.org/10.1007/ s12205-014-0196-9

22. Wong HS, Zobel M, Buenfeld NR, Zimmerman RW (2009) Influence of the interfacial transition zone and microcracking on the diffusivity, permeability and sorptivity of cement-based materials after drying. Mag Concr Res 61(8):571-589. https://doi.org/10.1680/macr.2008.61.8. 571

23. Wu Z, Wong HS, Buenfeld NR (2015) Influence of dryinginduced microcracking and related size effects on mass transport properties of concrete. Cem Concr Res 68:35-48. https://doi.org/10.1016/j.cemconres.2014.10.018

24. Schieß1 P, Bamforth P, Baroghel-Bouny V, Corley G, Faber M, Gehlen C, Helland S, Ishida T, Helene P, Markeset G, Nilsson LO, Rostam S (2006) fib bulletin 34: model code for service life design

25. NT BUILD 492 (1999) Concrete, mortar and cement-based repair materials: chloride migration coefficient from nonsteady state migration experiments. Nordtest, Espoo

26. Russo N, Gastaldi M, Marras P, Schiavi L, Strini A, Lollini F (2019) A preliminary study on the effects of cracks on chloride penetration in different concretes. In: Proceedings of the $\mathrm{V}$ workshop on the new boundaries of structural concrete, Milan, Italy, pp 315-324

27. Luping T, Sørensen H (1998) Evaluation of the rapid test methods for measuring the chloride diffusion coefficients of concrete, NORDTEST Project No. 1388-98. SP Report 1998:42, SP Swedish National Testing and Research Institute, Borås

28. Andrade C, Castellote M, d'Andrea R (2011) Measurement of ageing effect on chloride diffusion coefficients in cementitious matrices. J Nucl Mater 412(1):209-216. https://doi.org/10.1016/j.jnucmat.2010.12.236

29. Abyaneh SD, Wong HS, Buenfeld NR (2016) Simulating the effect of microcracks on the diffusivity and permeability of concrete using a three-dimensional model. Comput Mater Sci 119:130-143. https://doi.org/10.1016/j.commatsci. 2016.03.047

30. Russo N, Gastaldi M, Schiavi L, Strini A, Zanoni R, Lollini $\mathrm{F}$ (2020) Effect of cement type and micro-cracks on chloride penetration in concrete. Submitted for the 15th International conference on durability of building materials and components, to be held in UPC-BarcelonaTECH, 20-23 Oct 2020

Publisher's Note Springer Nature remains neutral with regard to jurisdictional claims in published maps and institutional affiliations. 